NASA Technical Memorandum 89877

AIAA-87-1976

\title{
Application of Single Crystal Superalloys for Earth-to-Orbit Propulsion Systems
}

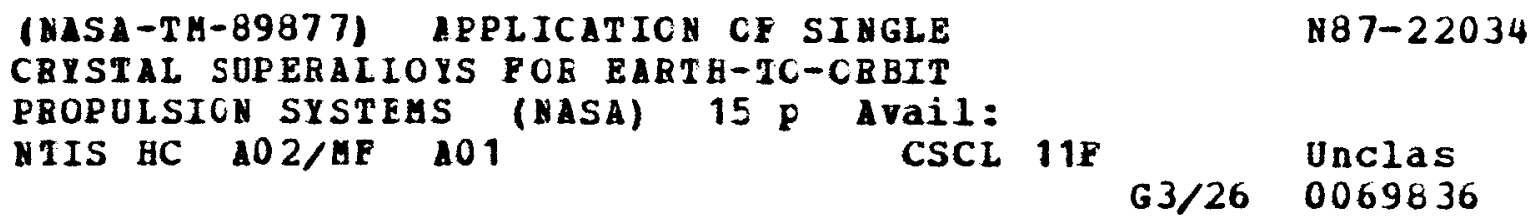

N87-22034

G3/26 0069836

R.L. Dreshfield

Lewis Research Center

Cleveland, Ohio

and

R.A. Parr

George C. Marshall Space Flight Center

Marshall Space Flight Center, Alabama

Prepared for the

23rd Joint Propulsion Conference

cosponsored by the AIAA, SAE, ASME, and ASEE

San Diego, California, June 29-July 2, 1987 
APPLICATION OF SINGLE CRYSTAL SUPERALLOYS FOR EARTH-TO-ORBIT PROPULSION SYSTEMS

\author{
R.L. Oreshfield \\ National Aeronautics and Space Administration \\ Lewis Research Center \\ Cleveland, Ohio 44135 \\ and \\ R.A. Parr \\ National Aeronautics and Space Administration \\ George C. Marshall Space Flight Center \\ Marshall Space Flight Center, Alabama 35812
}

\begin{abstract}
Single crystal superallcys were first identified as potentially useful engineering materials for aircraft gas turbine engines in the mid-1960's. Although they were not introduced into service as turbine blades in commercial aircraft engines until the early 1980's, they have subsequently accumulated tens of militions flight of hours in revenue producing service.

The space shuttle main engine (SSME) and potential advanced earth-to-orbit propulsion systems impose severe conditions on turbopump turbine blades which for some potential failure modes are more severe than in aircraft gas turbines. This paper will discuss research activities which are directed at evaluating the potential for single crystal superalloys for application as turbopump turbine blades in the SSME and advanced rocket engines.
\end{abstract}

\section{Introduction}

In the 1960's, Pratt and Whitney Aircraft pioneered the application of directionally solidified polycrystalline, nickel-base superalloys as turbine airfoils in aircraft propulsion systems. A natural extension of that technology was directionally solidified single crystal castings, which Pratt and Whitney Aircraft introduced into the engines which currently powers some commercial aircraft. Such a single crystal turbine blade for a Pratt and Whitney PW2037 turbofan engine is shown in Fig. 1. Single crystal turbine blades have now accumulated tens of millions of hours of service in both civilian and military aircraft.

The operating conditions for some turbines in advanced rocket engines are in some respects more severe than for aircraft turbine engines. Single crystal airfoils are now being evaluated for some applications in the space shuttle main engine (SSME) and similar propulsion systems. This paper will review selected materials requirements for rocket engine turbine airfoils with particular emphasis on the suitability of single crystal nickel-base superalloys.

\section{Background}

The Space Shuttle uses three SSME's during launch. The high pressure fuel and high pressure oxidizer pumps are both driven by combustion turbines which operate under conditions which differ from air breathing aircraft turbines. The operating conditions for advanced rocket engine high pressure turbopump turbines and aircraft turbines are compared in Table 1. Of particular significance is the fact that rocket turbines may operate in a hydrogen or hydrogen combustion environment at high pressure. This results in very high heat transfer coefficients and resultant severe temperature transients both in the gas stream and metal parts. Figure 2 is a schematic diagram comparing the materials operating realm for SSME and aircraft turbine airfoil materials. Note that the more severe thermal transients in the rocket engine turbines cause a greater strain range than is experienced in aircraft turbines. While the goal life of $7.5 \mathrm{hr}$ ( 55 launches) appears to be modest for the SSME, the severe low and high cycle fatigue conditions imposed on the turbine blades in a hydrogen environment have so far prevented achievement of the design life goal.

A study was performed by Rocketdyne to assess the relative merits of several classes of materials to lengthen the service life of the turbine blades for an advanced rocket engines like the SSME. 1 The materials considered are shown in Table 2. The study concluded that advanced single crystal superalloys warrant development for turbines operating at $870^{\circ} \mathrm{C}$. A useful advanced single crystal alloy would be one which would be resistant to property degradation in high pressure hydrogen and have fatigue properties superior to those single crystal alloys currently developed for aircraft propulsion.

\section{Single Crystal Superalloys}

\section{Mechanical Behavior}

Single crystal superalloys offer improved stress rupture life, low and high cycle fatigue life compared to directionally solidified (DS) polycrystalline superalloys. Figure 3 compares those three mechanical properties for NASAIR 100 single crystals and DS MAR-M 247, 2 the DS alloy from which NASAIR 100 was derived by eliminating carbon, cobalt and boron. Thermal shock testing of single crystal airfoil shapes in a rig which simulates SSME transients demonstrated greater than 70 percent life improvement over MAR-M 246+Hf airfoils. While the single crystal superalloys offer improvement over DS alloys which are currently bill of materials in the SSME, still further improvements appear to be achievable by the use of advanced processes. These will be discussed later.

Mechanical properties of single crystal superalloys are highly anisotropic. The data comparison in Fig. 3 is for crystals all oriented with an edge of the cubic crystal parallel to the 
applied load. Young's modulus at room temperature varies from about $124 \mathrm{GPa}$ for the cube edge direction, <100> to about $290 \mathrm{GPa}$ for the cube body diagonal direction, <111>. Similarly yield strength, ultimate strength and other mechanical properties are dependent on the crystallographic orientation of the sample or blade and must be considered in the design. The effect of orientation on the LCF life of a single crystal alloy is shown in Fig. 4. It $c$ an be seen that when the total strain range is constant, the greatest life is for crystals having a $<100>$ orientation and the shortest life is for crystals having a $<111\rangle$ orientation. If, however, the strain is normalized by multiplying by the modulus, all three orientations studied fall on the same line. 4

\section{Advanced Processes}

One failure mode causing severe life limitation in the SSME is fatigue. In conventional carbon bearing superalloys, failure initiation is often associated with carbides. Because most single crystal superalloys contain no intentionally added carbon, the crack initiation site is typically at a pore.

One processing method that has been shown to produce low porosity castings is high gradient directional solidification. ${ }^{5}$ Single crystals grown at $250{ }^{\circ} \mathrm{C} / \mathrm{cm}$ were found to have about 0.1 percent porosity compared to 0.5 percent for those grown at $50^{\circ} \mathrm{C} / \mathrm{cm}$. The latter gradient is typical of the highest gradients commercially available. The crystals grown at $250^{\circ} \mathrm{C} / \mathrm{cm}$ demonstrated about an order of magnitude improvement in high cycle fatigue life at $870^{\circ} \mathrm{C}$ compared to crystals grown at $50^{\circ} \mathrm{C} / \mathrm{cm}$ as shown in $\mathrm{Fig} .5$. Currently, there is no commerical production capability having the higher thermal gradient.

An alternative method of reducing porosity is the use of hot isostatic pressing (HIP). It has been used to reduce the amount and size of porosity in superalloy castings for over a decade. Figure 6 shows that the application of HIP to an experimental single crystal superalloy can increase its LCF life threefold. 6

The application of HIP to improve fatigue properties appears to offer the best near term opportunity for single crystal superalloys. However the process needs to be adapted for the particular alloy and component. Earlier it was mentioned that most single crystal superalloys have no intentionally added carbon. If carbon should inadvertently contaminate the component during HIPing, the incipient melting point of the alloy would be reduced and it may no longer be capable of being properly heat treated. Carbides might also precipitate in the alloy and become crack initiation sites in service. Figure 7 demonstrates that carbon impurities in the HIP atmosphere can react with the alloy and cause both incipient melting and carbide precipitation. In this experimental HIP run, a carbon-free single crystal alloy was HIPed in an autoclave which had a carbon furnace. We believe that the carbon reacted with residual oxygen in the vessel to cause a carburizing atmosphere. The added carbon reduced the incipient melting point to below the working temperature and some melting of the sample occurred. Carbides precipitated on cooling from the HIP temperature. One must carefully control the atmosphere during the HIP process to avoid such microstructures.

Carbon and boron are usually intentionally added to cast polycrystalline superalloys to strengthen their grain boundaries. Since the single crystal alloys do not have those elements to allow higher temperature solution heat treatment, care must be taken to avoid using parts which inadvertently contain additional grains. Figure 8 is an example of a turbine blade which was thought to have been a single crystal when it was run for about $2 \mathrm{hr}$ in a rotating rig test at elevated temperature. ${ }^{2}$ The blade was in fact designed to operate several thousand hours at a temperature greater than that to which this was exposed, but as can be seen in the figure the blade cracked. It was later concluded that the blade had received abusive handling prior to the solution heat treatment and recrystallized during the solution heat treatment. It should be noted, however, that recrystallization may occur during the casting process or during the HIP process. Thus, all processes must be carefully controlled and inspection methods must be in place to assure that only high quality single crystal blades enter service.

Rocketdyne is studying single crystal superalloys cast by conventional thermal gradient and commerically available high gradient casting processes for application as SSME turbine blades in contract NAS3-24646. The test materials made by both casting processes will be subjected to HIP processing and it is anticipated that a suitable process will be identified for manufacturing single crystal turbine blades with improved fatigue resistance. As a part of the overall SSME program, Rocketdyne is also evaluating the use of conventionally processed and HIP'ed single crystals for application in the high pressure pumps.

\section{Other Considerations:}

The SSME turbine blades airfoils operate in a hydrogen - steam mixture. Cooler regions such as the dovetail are exposed to essentially pure hydrogen in the fuel pump. The effects of hydrogen on the mechanical properties must therefore be considered. It is generally accepted that for nickel-base superalloys, the greatest degradation in properties is most likely to occur near room temperature rather than at extreme cryogenic or elevated temperatures.

To screen candidate alloys room temperature tension tests of both smooth and notch bars were performed in $34 \mathrm{MPa}$ hydrogen and helium in the $<100>$ direction. The tensile strength of several single crystal superalloys in helium is shown in Fig. 9. Note that all alloys are notch strengthened in He. Figure 10 shows the tensile strength of the same alloys tested in hydrogen. note that most alloys have significantly reduced notch strength compared to smooth bar strength. The degradation of the notch strength in hydrogen in summarized in Fig. 11 which shows the ratio of the notch strength in hydrogen to that in helium. The data appears to fall into three groups. The best alloys, AF56 and $\mathrm{N}-5$, have a ratio of 0.84 an are significantly superior to all others. A second intermediate group of alloys, PWA 1480, RR2000 and $\mathrm{N} 4$, have ratios slightly less than 0.5 . (It 
should be noted that in a subsequent test series PWA 1480 had a notch ratio of 0.59 ). The remaining alloys have a ratio below 0.4 . The single crystal form of the current bill of materials for the SSME, MAR M-246, has a ratio of 0.18 and does not significantly differ from the $O S$ form. One alloy, CMSX-2 was given two different heat treatments. It can be seen that the effect of hydrogen was virtually unchanged. While there has been a great difference in the behaviour of the alloys studied, to date we have been unable to rationalize the differences among alloys.

The amount of plastic deformation sustained by the alloys prior to fracture is lower for specimens tested in hydrogen. The scanning electron micrographs in Fig. 12 compare secondary cracks on the surface of $\mathrm{N}-5$ samples tested in $\mathrm{He}$ and $\mathrm{H}_{2}$. It can be seen that the litt?a plasticity is apparent in the $\mathrm{H}_{2}$ tested material compared to the one tested in $\mathrm{He}$.

The detrimental effect of porosity on the fatigue life of single crystal superalloys was cited earlier. Recent research has also shown that hydrogen embrittlement is enhanced by the presence of internal voids which trap the hydrogen.' Thus, when the material is exposed to conditions which might be expected to allow the hydrogen to escape from the part, the hydrogen may be retained in the pore and still cause embrittlement.

The anisotropy of the mechanical properties of single crystal superalloys was briefly discussed earlier. A high degree of anisotropy is also observed in the effect of hydrogen on a single crystal superalloys. Figure 13 summarizes the degradation of notch tensile strength of PWA 1480 in room temperature hydrogen. The greatest degradation occurs for the $\langle 100\rangle$ direction, while the least is for the $\langle 111\rangle$ direction. (The difference between the 0.59 notch ratio shown here and the 0.49 shown previously is believed to reflect differences in the test lots and may not be significant.) The reason for the degradation in anisotropy is not understood at this time. The implications of this anisotropy on the design of blades are being evaluated.

\section{Concluding Remarks}

Single crystal turbine blades are in commerical and military service in gas turbine powered aircraft. An obvious extension of those applications is the use of single crystal materials for airfoils in the turbines in rocket engines. Current technology single crystal alloys offers the potential for improved life in SSME turbines and advanced processing offers potential for even greater improvements. Programs are currently in progress to evaluated the potential for single crystal alloys for rocket engines for earth-toorbit propulsion systems and it is expected that these newly developed alloys will soon be flight qualified for such systems.

\section{References}

1. Chandler, W.T., "Materials for Advanced Rocket Engine Turbopump Turbine Blades," Advanced High Pressure $0_{2} / \mathrm{H}_{2}$ Technology, S.F. Morea and S.T. Wu, eds., NASA CP-2372, Washington, D.C., 1985, pp. 110-132.

2. Strangman, T.E., Heath, B. and Fujii, M., "Low-Cost Single-Crystal Turbine B lades," Vol.1, GARRETT-21-4314-1, Garrett Turbine Engine Company, Phoenix, AZ, Nov. 1983. (NASA CR-168218).

3. Ryan, R.M. and Gross, L.A., "Effects of Geometry and Materials on Low Cycle Fatigue Life of Turbine Blades in LOX/Hydrogen Rocket Engines," AIAA Paper 86-1443, June 1986.

4. Gabb, T.P., Gayda, J. and Miner, R.V., "Orientation and Temperature Dependence of Some Mechanical Properties of the SingleCrystal Nickel-Base Superalloy Rene N4: Part II. Low Cycle Fatigue Behavior," Metallurgical Transactions A, Vol. 17, No. 3, Mar. 1986, pp. 497-505.

5. Khan, T. and Caron, P., "The Effect of Processing Conditions and Heat Treatments on the Mechanical Properties of a Single Crystal Superalloy," ONERA-TP-1985-15, Feb. 1985.

6. Jablonski, D.A. and Sargent, S., "Anisotropic Fatigue Hardening of a Nickel Base Single Crystal at Elevated Temperature," Scripta Metallurgica, Vol. 15, No. 9, Sept. 1981, pp. 1003-1006.

7. Baker, C.L., Chene, J., Kromp, W., Pinczolitis, H., Bernstein, S.M. and Williams, J.C., "Role of Hydrogen and Structure on CMSX-2," Structural Integrity and Durability of Reusable Space Propulsion Systems, NASA CP-2381, Washington, D.C. 1985, pp. 17I-180. 
TABLE I. - COMPARISON OF ROCKET ENGINE AND AIRCRAFT ENGINE

TURBINE OPERATIONS

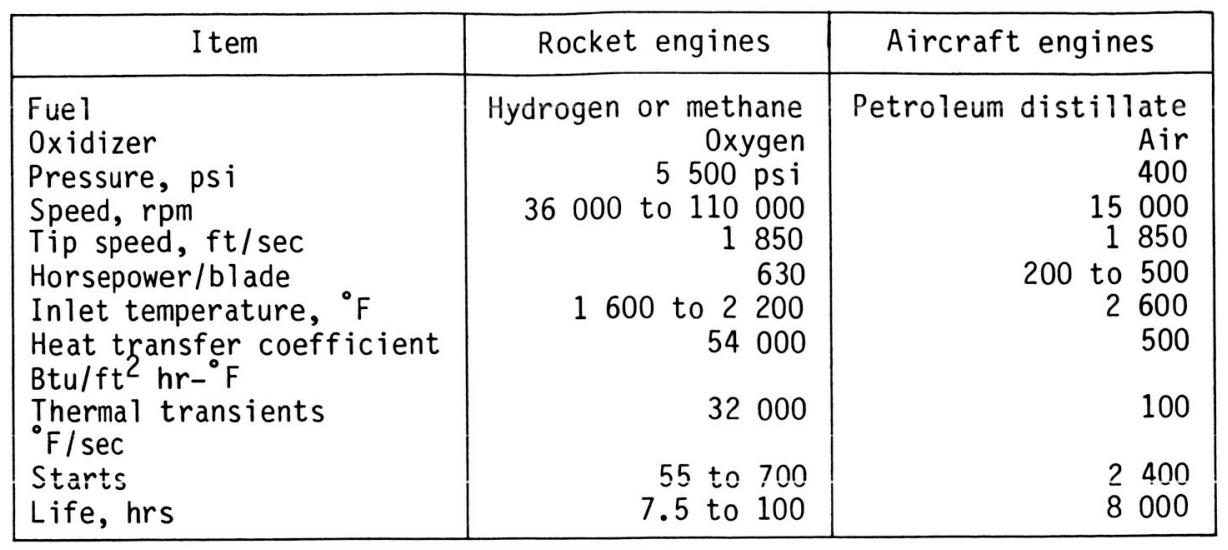

TABLE II. - POTENTIAL ADVANCED

BLADE MATERIALS

Directionally solidified MAR-M $246+\mathrm{Hf}$

Single crystal superalloys

Directionally solidified eutectic alloys

Fiber reinforced superalloys

Rapid solidification superalloys

Monolithic ceramics

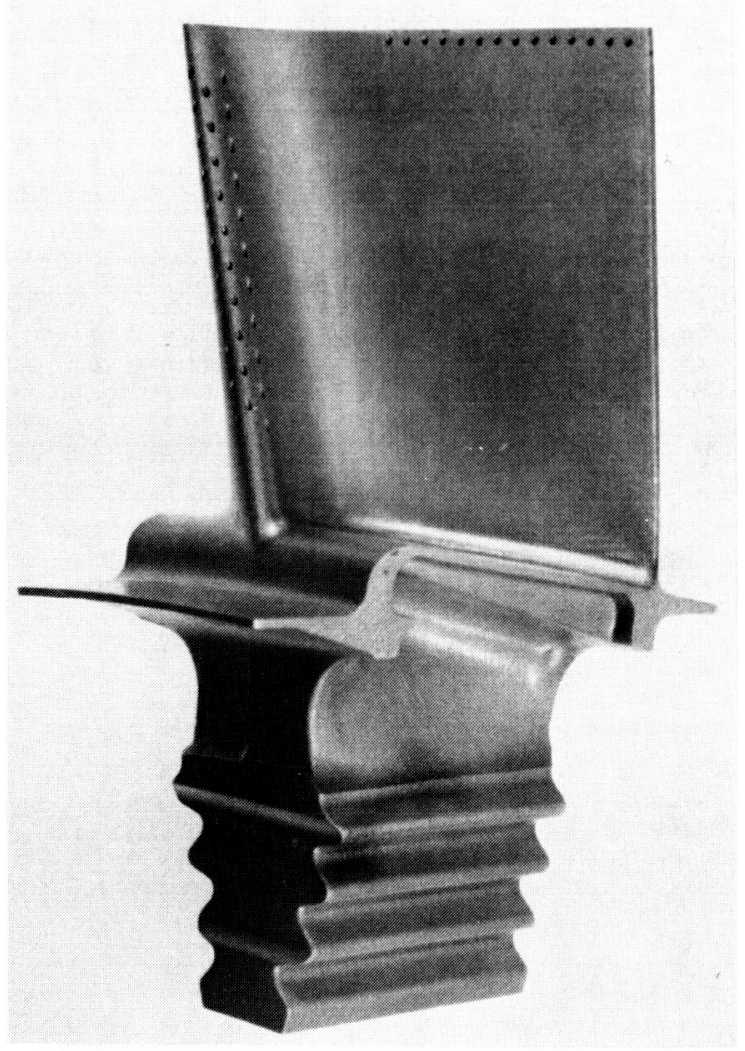

ORGMAL PAGE OF POOR OUALITY

FIGURE 1. - SINGLE CRYSTAL TURBINE BLADE USED IN PdWA 2037 ENGINE. 

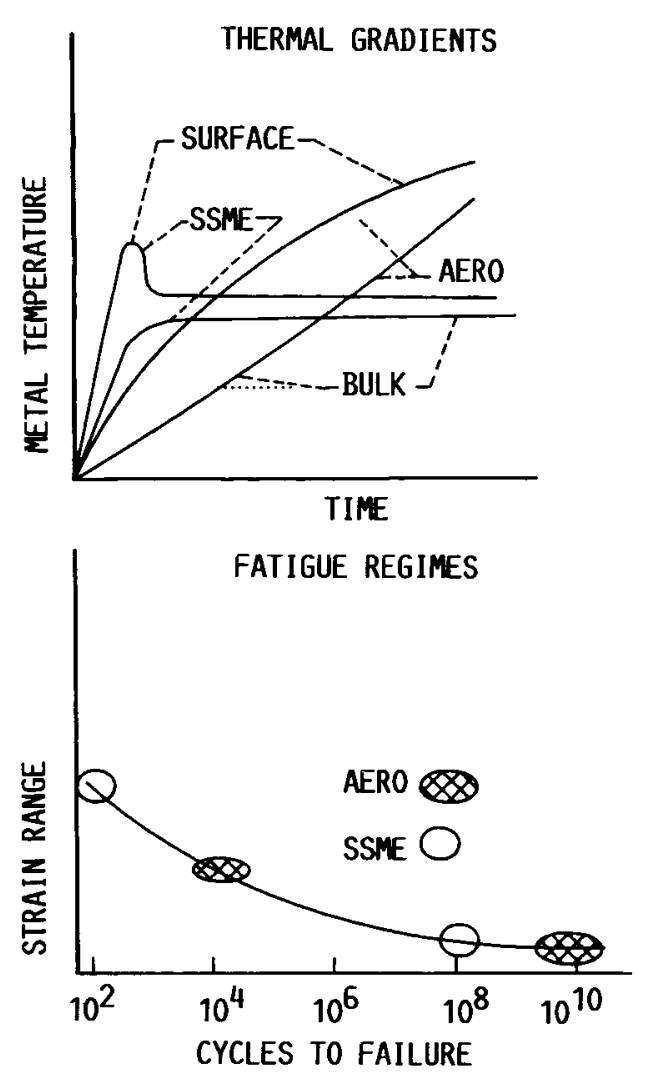

CYCLIC STRESS-STRAIN RESPONSE
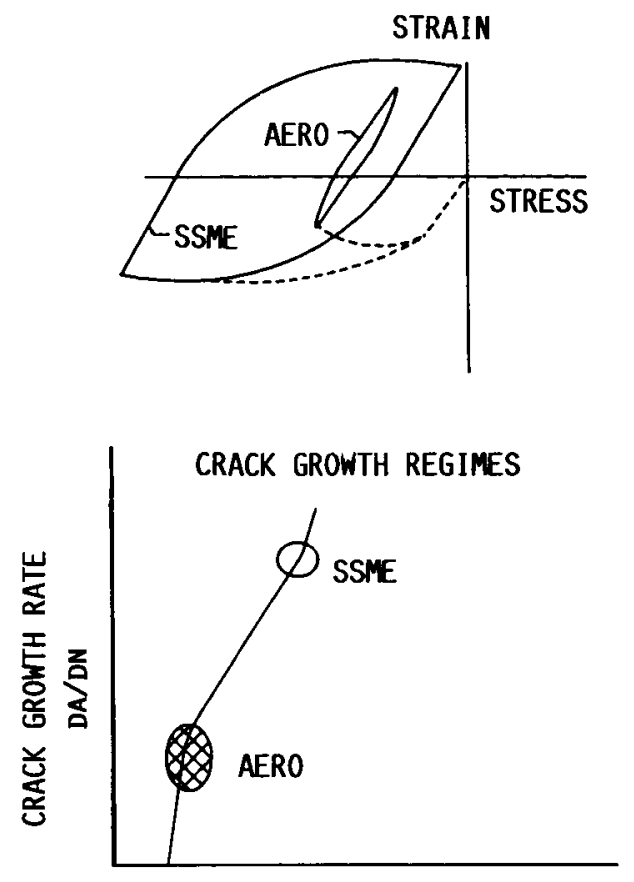

STRESS INTENSITY RANGE

FIGURE 2. - COMPARISON OF SSME AND AERO TURBINE BLADE MATERIALS OPERATING REGIMES.

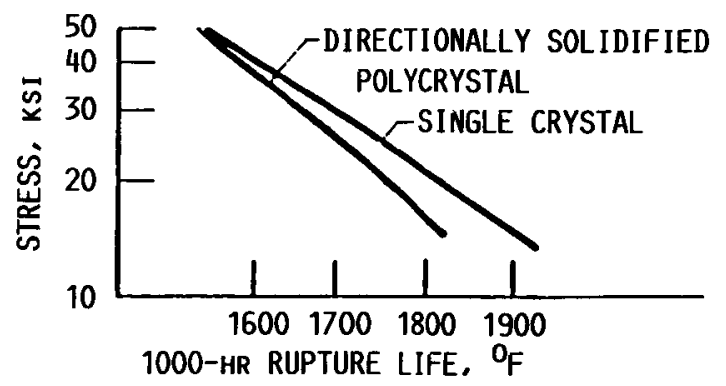

(A) STRESS RUPTURE.

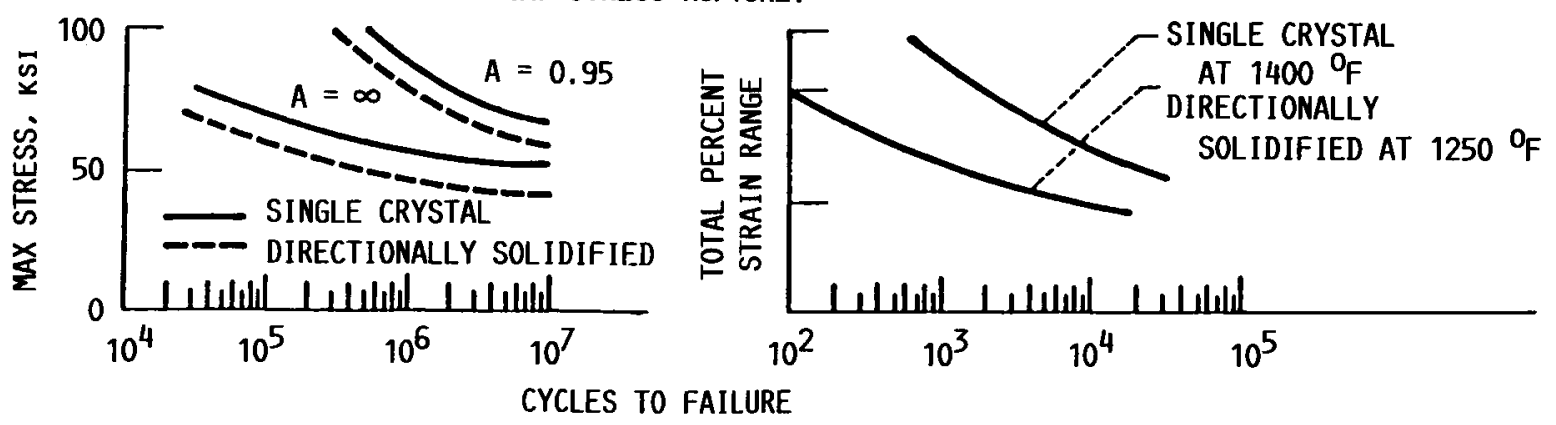

(B) HCF. (C) LCF.

FIGURE 3. - SINGLE CRYSTAL ALLOYS HAVE MECHANICAL PROPERTIES SUPERIOR TO DIRECTIONALLY SOLIDIFIED ALLOYS. 


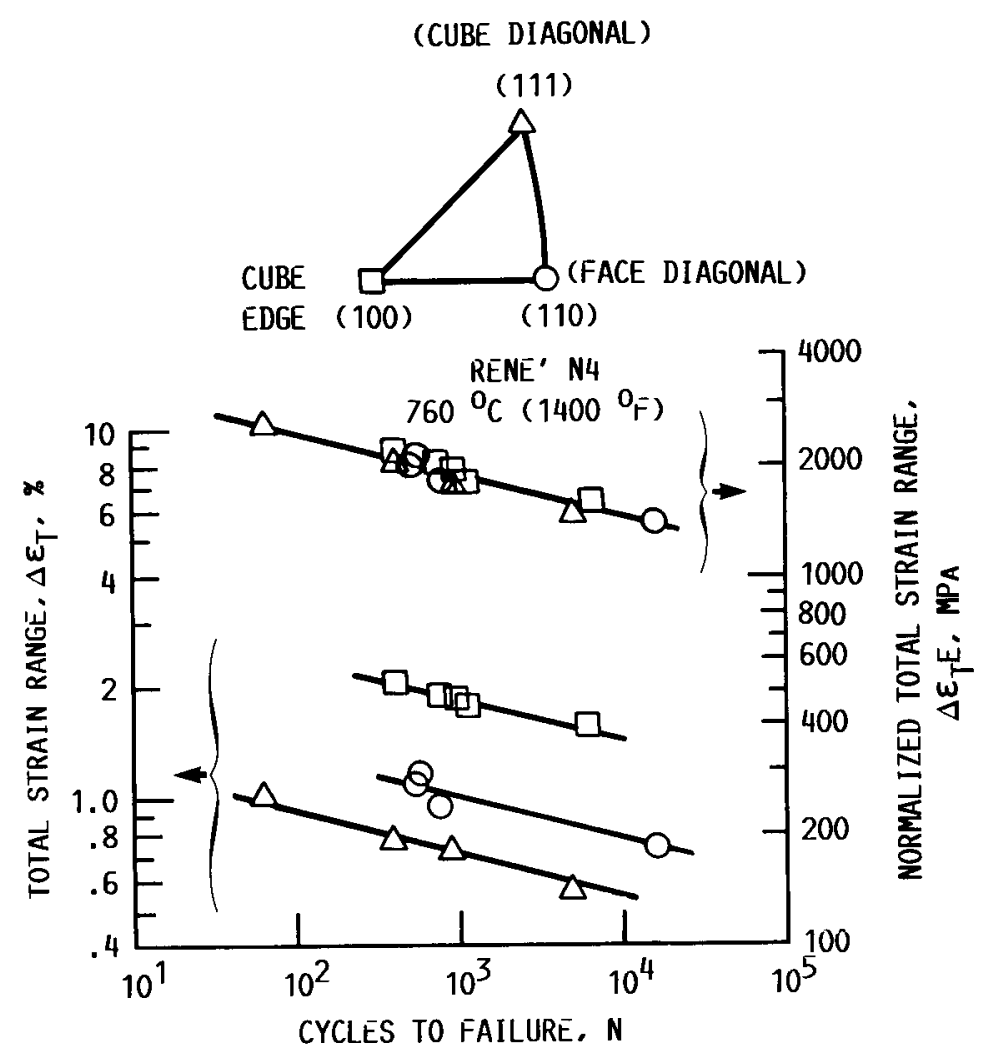

FIGURE 4. - LCF ANISOTROPY OF A SINGLE CRYSTAL SUPERALLOY.

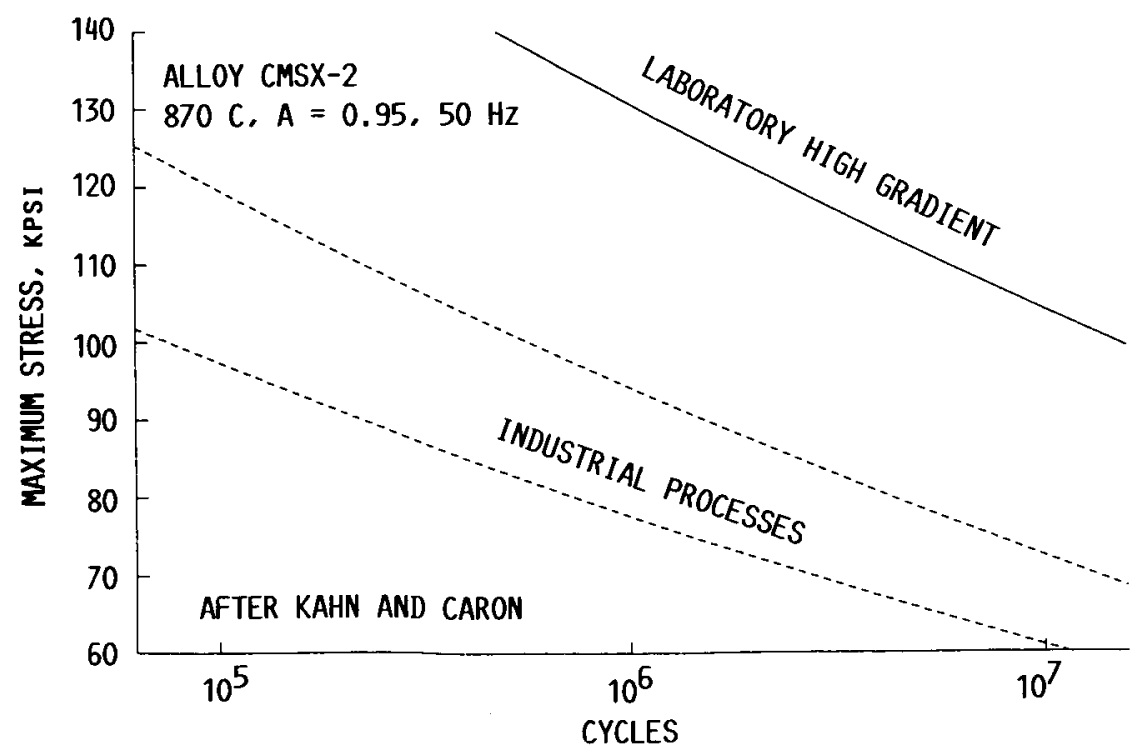

FIGURE 5. - HIGH GRADIENT SOLIDIFICATION IMPROVES HIGH CYCLE FATIGUE LIFE OF SINGLE CRYSTALS. 


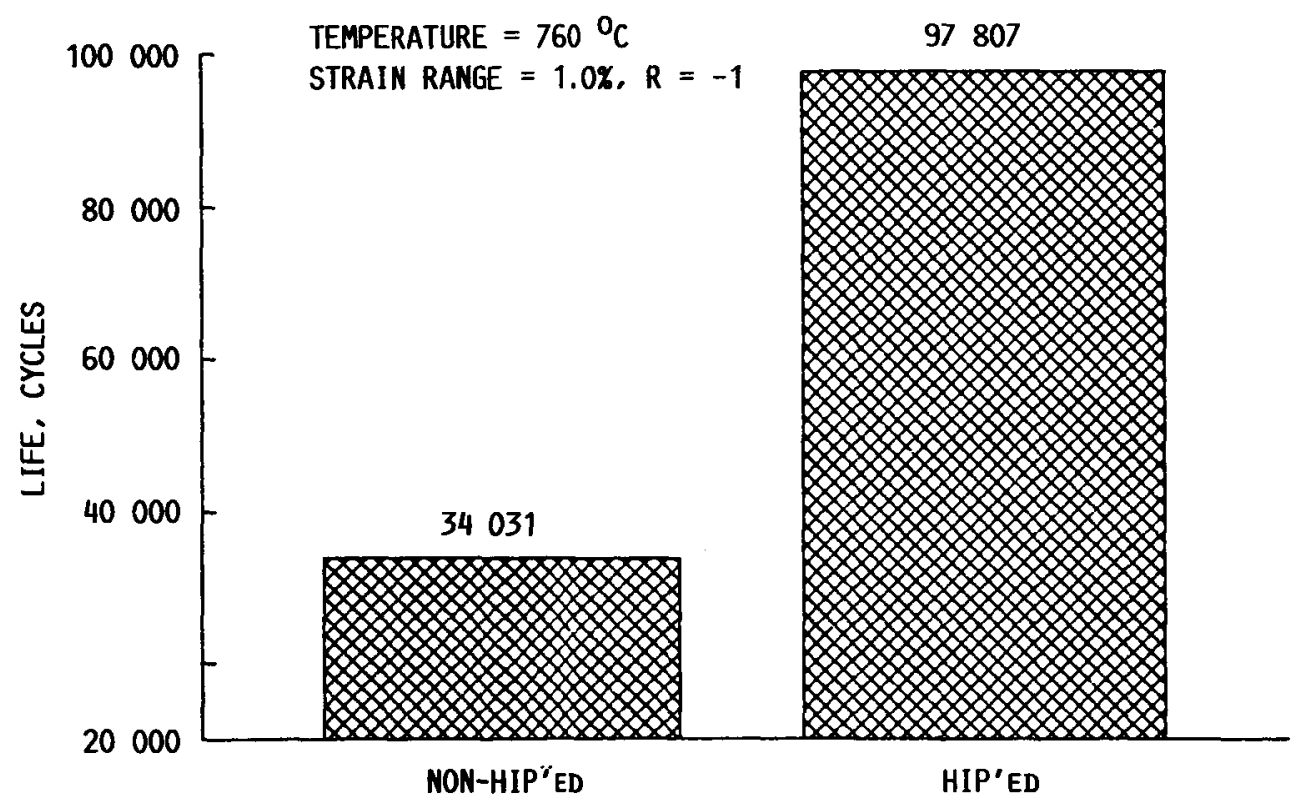

FIGURE 6. - HIP IMPROVES LCF LIFE OF SINGLE CRYSTALS.

DATA FROM JABLONSKI AND SARGENT 
ORIGINAL PACE IS

OF POOR QUALTY
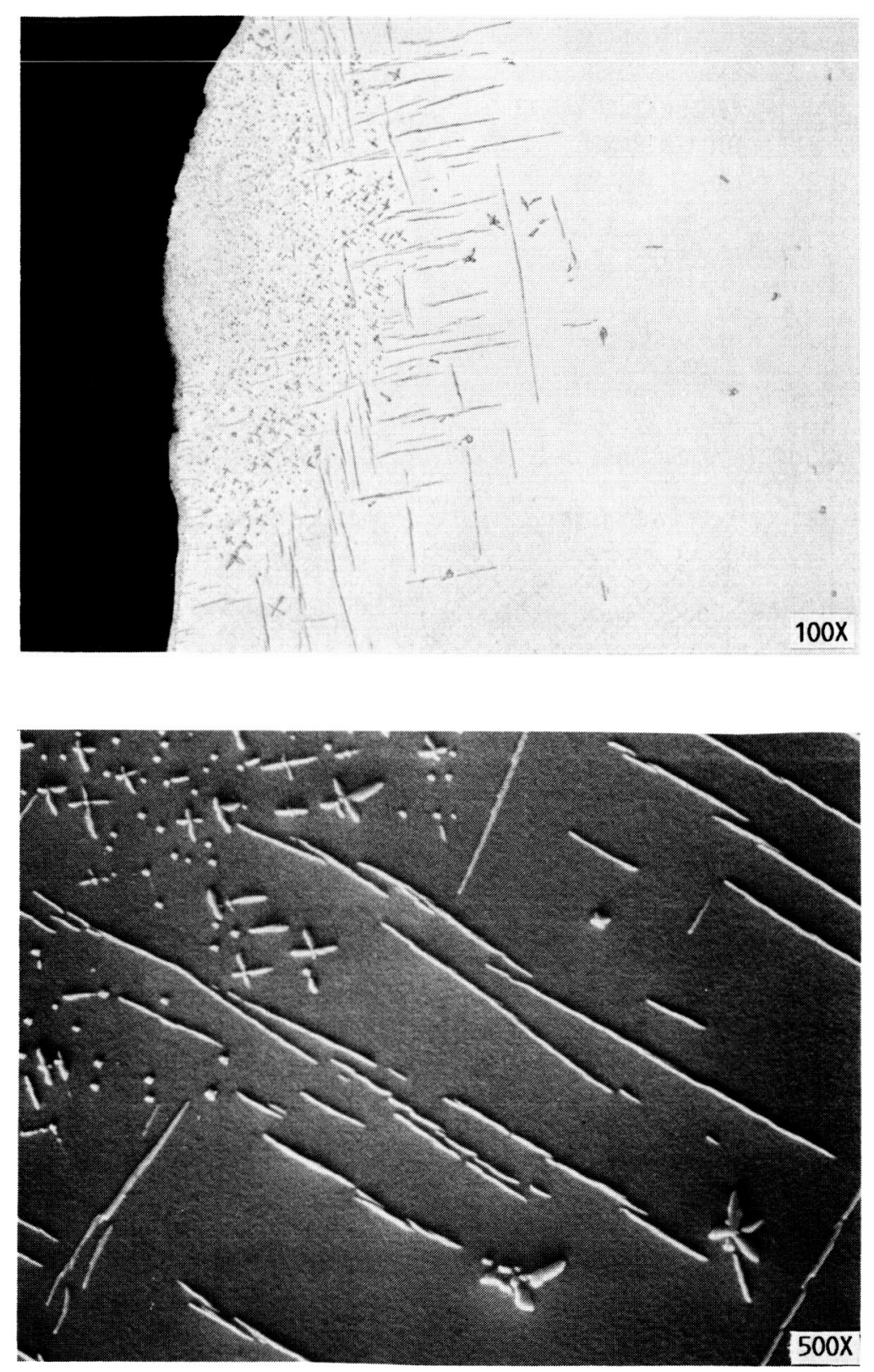

ALLOY CMSX 2

HIP 2 HR, $23800^{\circ} \mathrm{F}$

FigURE 7. - HIP ATMOSPHERE CAN CAUSE CARBURIZATION AND MELTING. 
ORIGINAL PACE IS

OF POOR QUALITY

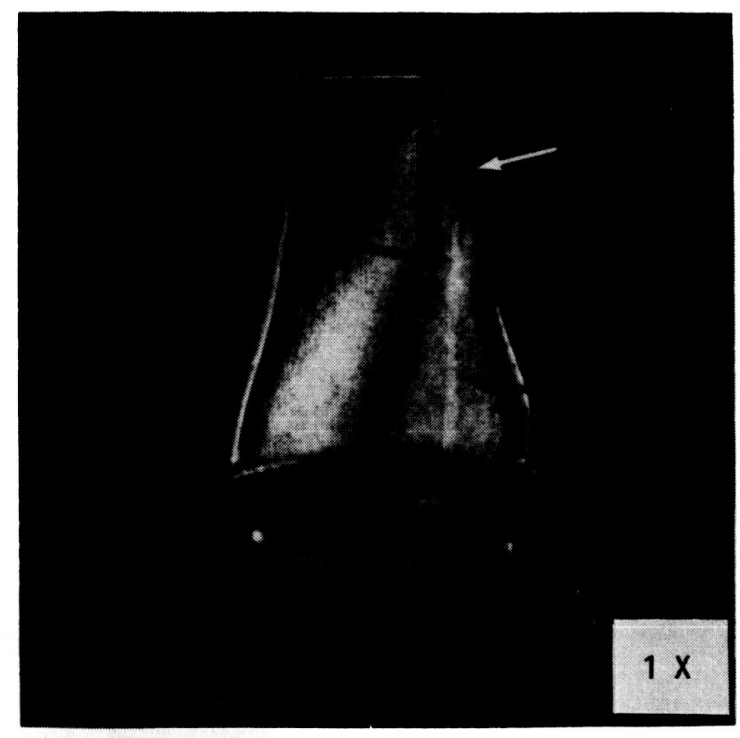

BLADE A25

CRACK OPENED FOR STUDY

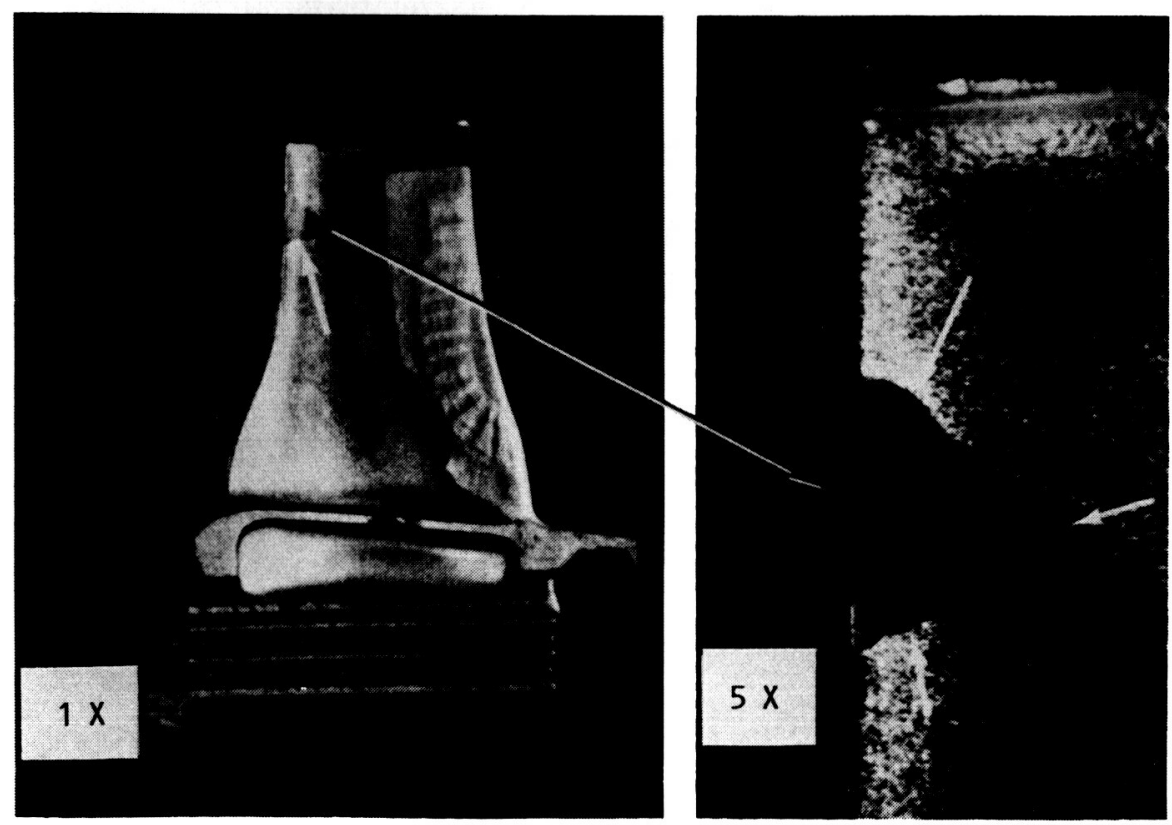

BLADE A41

APPROX. 1 HR IN ROTOR RIG

FIGURE 8. - SINGLE CRYSTAL ALLOYS WILL NOT TOLERATE RECRYSTALLIZATION. 
PRESSURE $=34 \mathrm{MPA}$

SMOOTH BARS

\begin{tabular}{|c|c|c|c|c|}
\hline & & & & \\
\hline & 1000 & & 1500 & \\
\hline 1128 & b & AF 56 & QXXXXXXXXXXXX & 1538 \\
\hline 1142 & mon & $N-5$ & $\triangle \triangle \triangle \triangle \triangle \triangle \triangle \triangle \triangle \triangle \triangle \triangle$ & 1438 \\
\hline 1152 & 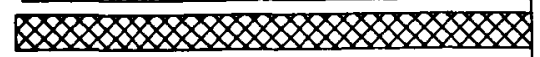 & PWA 1480 & $\triangle \times \times \times \times \times \times \times \times \times \times \times \times$ & 1518 \\
\hline 930 & x & RR 2000 & XXXXXXXXXXX & 1416 \\
\hline 1158 & bx & N4 & 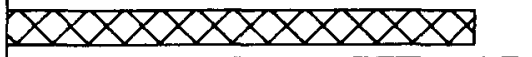 & 1473 \\
\hline 1087 & W & CMSX-4C & 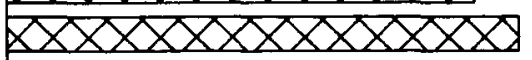 & 1537 \\
\hline 950 & m & SC180 & $\times \times \times \times \times \times \times \times \times \times \times \times \times \times 8$ & 1535 \\
\hline 1010 & W & SRR 99 & XXXXXXXXXXXX & 1419 \\
\hline 1092 & mancm & MAR M 246 & $\triangle \triangle \triangle \triangle \triangle \triangle \triangle \triangle$ & 1201 \\
\hline 1028 & x女y & CMSX-30 & $\triangle \times X \times \times \times X X \times \times X \times X X$ & 1551 \\
\hline 1046 & 2000 & CMSX $-2 \mathrm{~cm}$ & $\triangle X X \times X \times X \times X \times X \times X$ & 1499 \\
\hline
\end{tabular}

STRENGTH, MPA

FIGURE 9. - TENSILE STRENGTH OF SINGLE CRYSTAL SUPERALLOYS IN HIGH PRESSURE HELIUM.

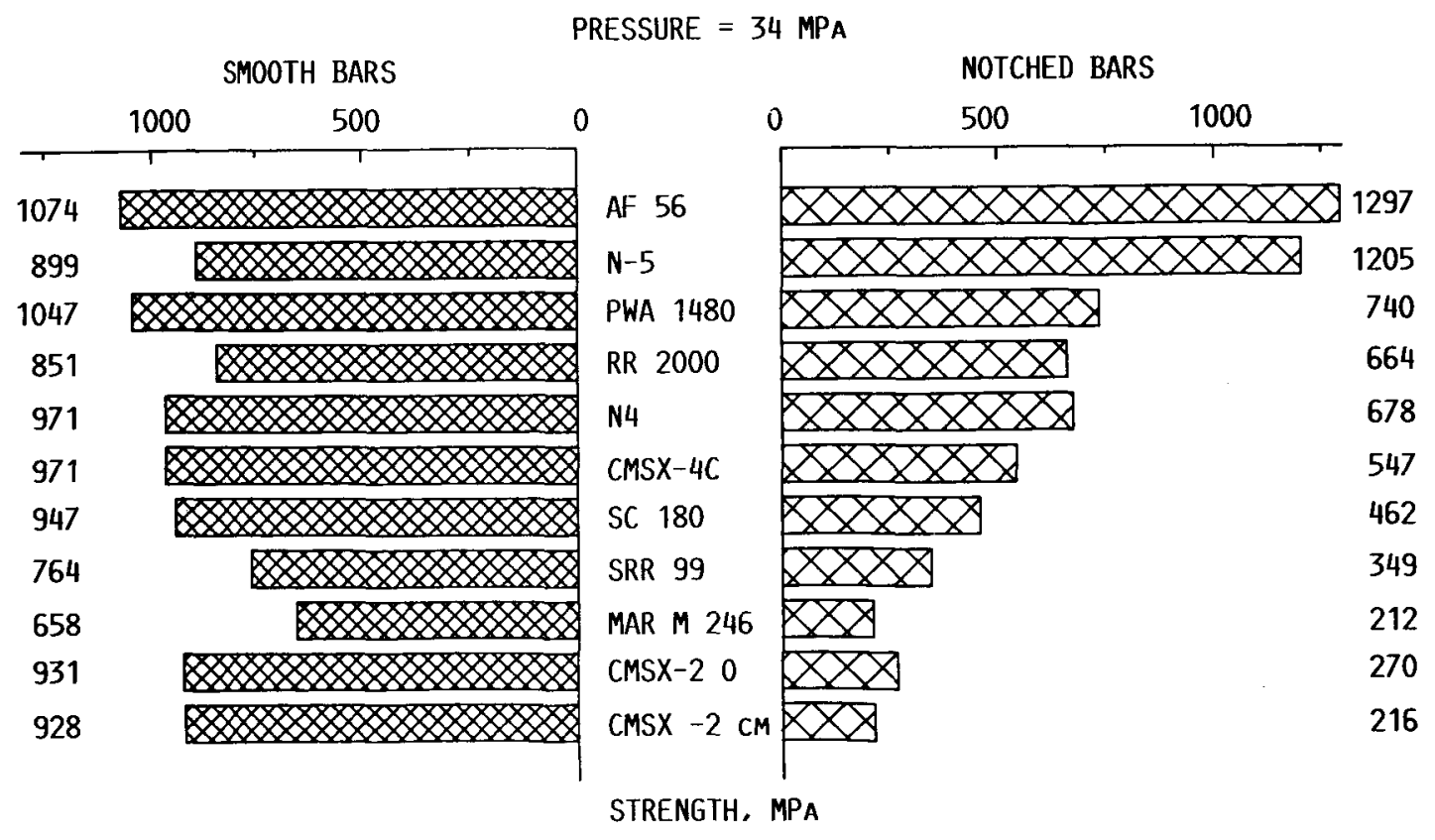

FIGURE 10. - TENSILE STRENGTH OF SINGLE CRYSTAL SUPERALLOYS IN HIGH PRESSURE HYDROGEN. 


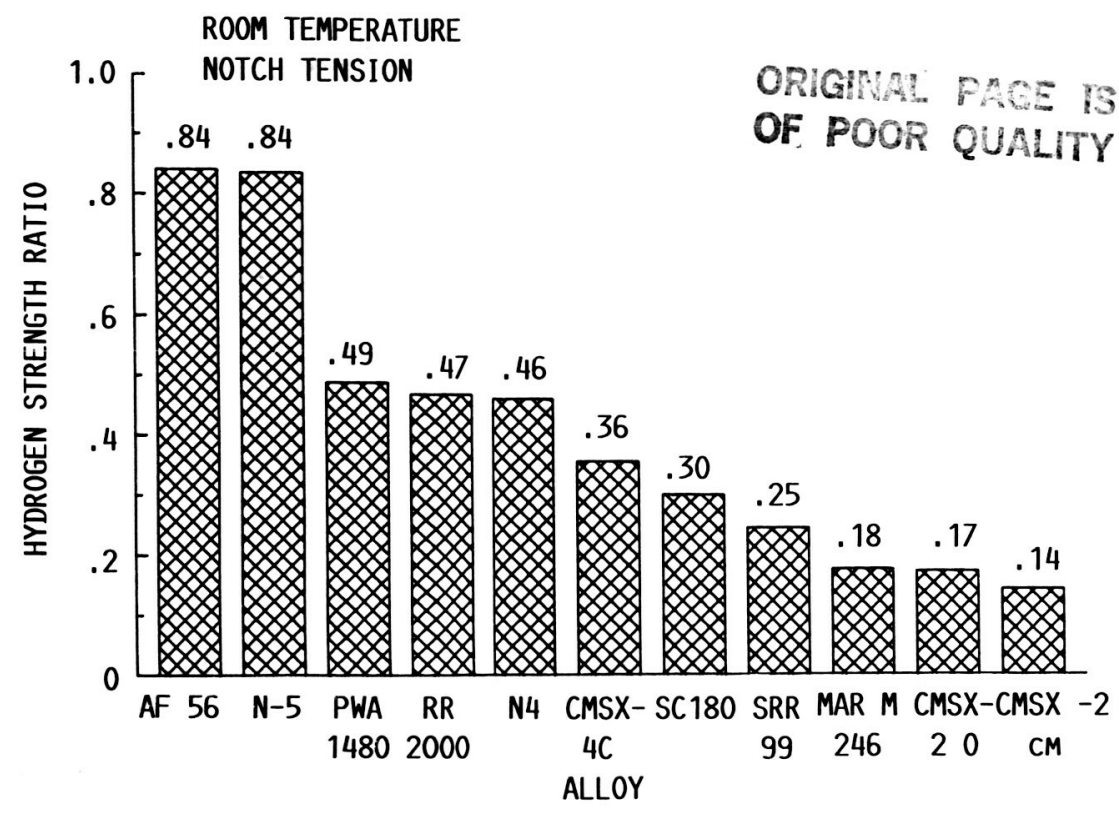

FIGURE 11. - RANKING OF SINGLE CRYSTAL SUPERALLOYS IN HIGH PRESSURE HYDROGEN.

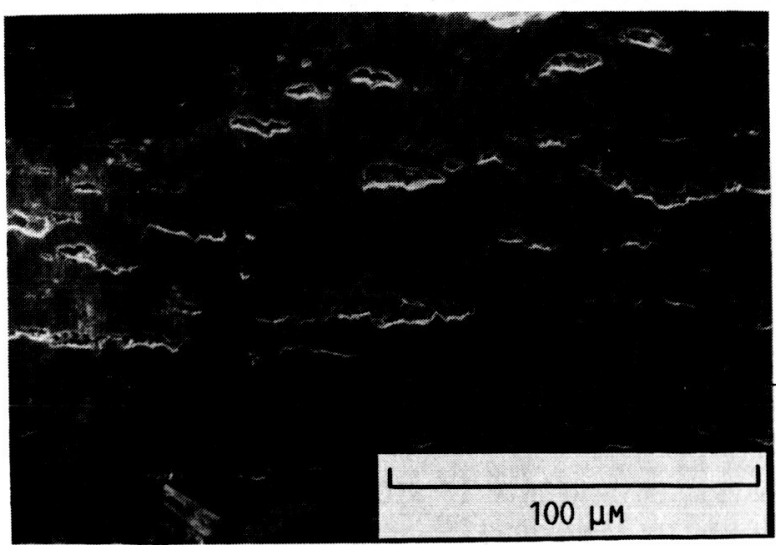

HELIUM

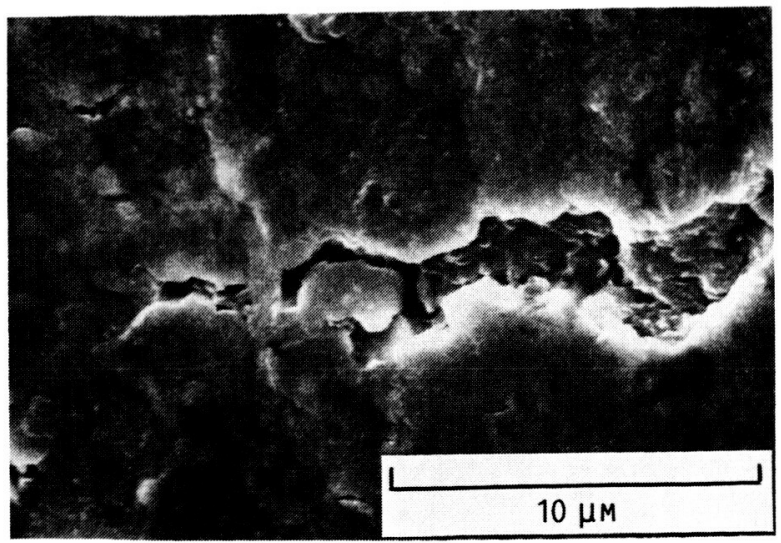

HEL IUM

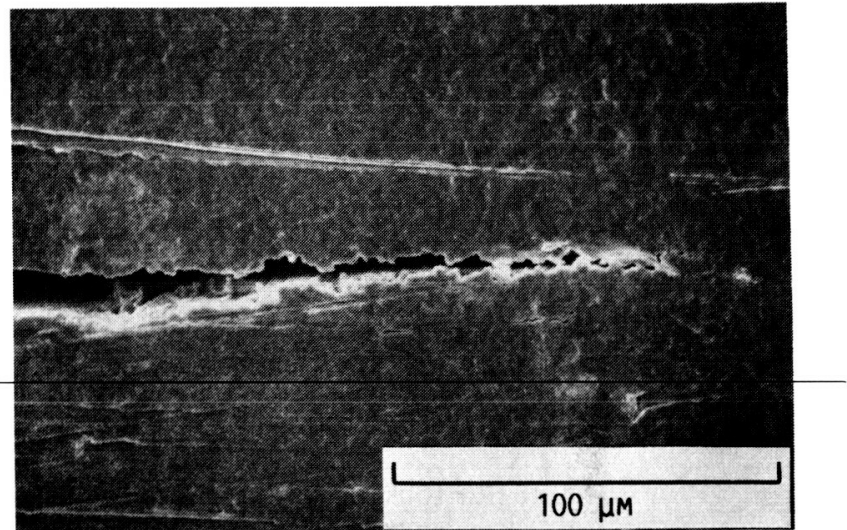

HYDROGEN

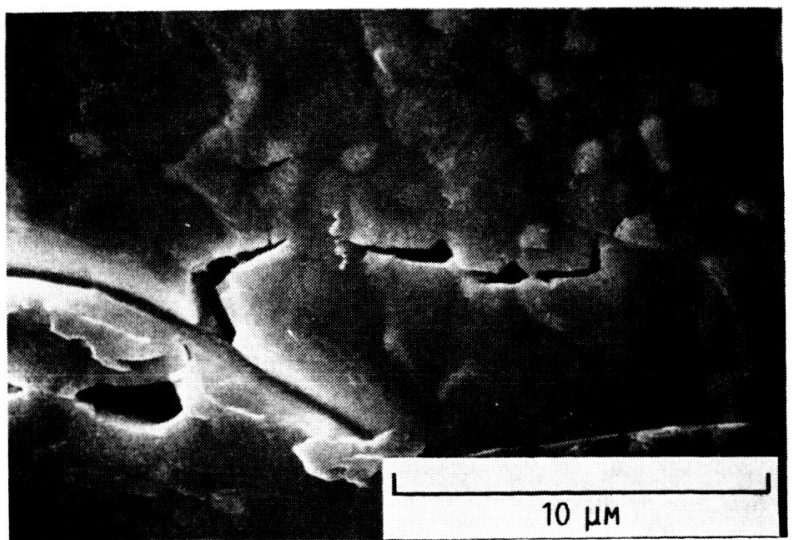

HYDROGEN

FIGURE 12. - TENSILE TESTS IN HYDROGEN HAVE LITTLE PLACIDITY. 


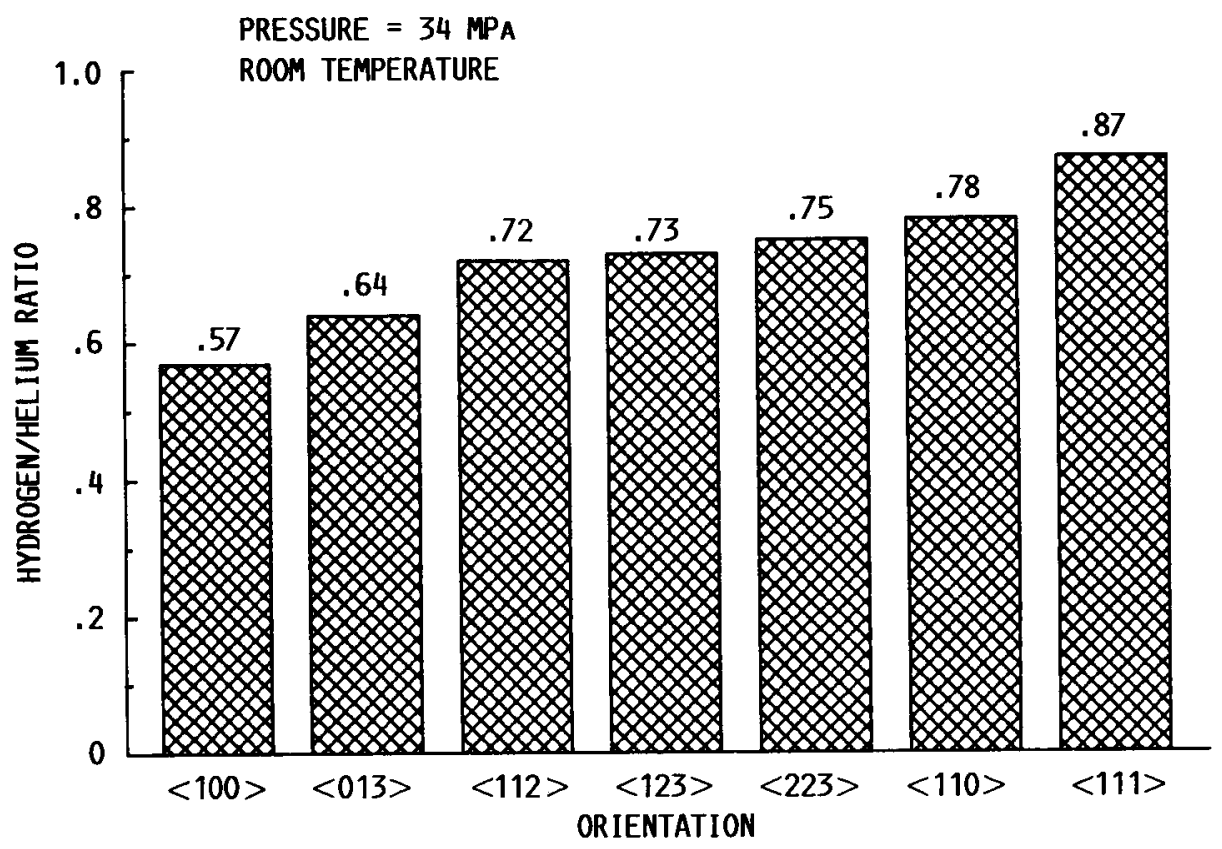

FIGURE 13. - ANISOTROPY OF DEGRADATION OF STRENGTH IN HIGH PRESSURE HYDROGEN OF A SINGLE CRYSTAL SUPERALLOY, PWA 1480. 


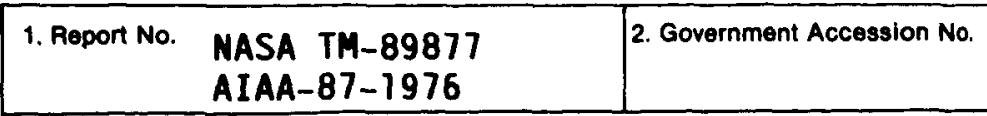

4. Title and Subtitle

AIAA-87-1976
Application of Single Crystal Superalloys for Earthto-Orbit Propulsion Systems

7. Author(s)

R.L. Dreshfield and R.A. Parr
3. Recipient's Catalog No.

5. Report Date

6. Performing Organization Code

$506-43-11$

8. Performing Organization Report No.

$E-3556$

10. Work Unit No.

11. Contract or Grant No.

13. Type of Report and Period Covered

Technical Memorandum

14. Sponsoring Agency Code

National Aeronautics and Space Administration Washington, D.C. 20546

15. Supplementary Notes

Prepared for the 23rd Joint Propulsion Conference, cosponsored by the AIAA, SAE, ASME, and ASEE, San Diego, California, June 29 - July 2, 1987. R.L. Dreshfield, NASA Lewis Research Center; R.A. Parr, George C. Marshall Space Flight Center, Marshall Space Flight Center, Alabama 35812.

16. Abstract

Single crystal superalloys were first identified as potentially useful engineering matertals for aircraft gas turbine engines in the mid-1960's. Although they were not introduced into service as turbine blades in commercial aircraft engines until the early 1980 's, they have subsequently accumulated tens of millions filght of hours in revenue producing service. The space shuttle main engine (SSME) and potential advanced earth-to-orbit propulsion systems impose severe conditions on turbopump turbine blades which for some potential fallure modes are more severe than in aircraft gas turbines. Ints research activities which are directed at evaluating the potential for single crystal superalloys for application as turbopump turbine blades in the SSME and advanced rocket engines

$$
\text { Case discussed. The mechanical properties of these }
$$

alloys are summarined and the effects of hydrogen are noted.

Advanced processimgethe the use of high gradiet directional solidification and hot isostatic pressing to improve fatigue properties is also addressed.

17. Key Words (Suggested by Author(s))

Single crystal alloys; Nickel-base alloys; Unclassified - unlimited

Superalloys; Turbines; Rocket engines STAR Category 26 